\title{
Problematizando o conceito de deficiência a partir das noções de autonomia e normalidade
}

\author{
Questioning the concept of disability \\ based on the notions of autonomy and normality
}

Paula Gaudenzi ${ }^{1}$

Francisco Ortega ${ }^{2}$

${ }^{1}$ Instituto Nacional de

Saúde da Mulher, da

Criança e do Adolescente,

IFF, Fiocruz. Fiocruz.

Av. Rui Barbosa 716,

Flamengo. 22250-020 Rio

de Janeiro RJ Brasil.

paula.gaudenzi@gmail.com

${ }^{2}$ Instituto de Medicina

Social, UERJ. Rio de Janeiro

RJ Brasil.

\begin{abstract}
This is a conceptual theoretical study to reflect upon disability and some basic concepts that are involved in its profiling. The scope of the article is to broaden the outlook upon disability removing it from a description that reduces it to an ailment. For this purpose, we situated the Disability Studies historically presenting the Medical and Social Models of Disability and problematized the concepts of autonomy and normality. These concepts and their correlated aspects - independence, functionality and the norm - are used as a tacit touchstone to differentiate some bodily variations that are identified as different lifestyles from others that are often called disabilities. We conclude by stating that disability can be analyzed based on other interpretations that do not construe it as a synonym for ailment if we consider the notions of interdependence, normativity and creation of the self in the world as basic concepts to describe it. Key words Disability, Medical model of disability, Social model of disability, Autonomy, Normality
\end{abstract}

Resumo Trata-se de um estudo teórico conceitual para pensar a deficiência e alguns conceitos -base que são manejados para a caracterização da mesma. O objetivo do artigo é ampliar o olhar sobre a deficiência retirando-a de uma descrição que a reduza à doença. Para tanto, situamos historicamente os Disabilty Studies apresentando os Modelos Médico e Social da Deficiência e problematizamos os conceitos de autonomia e normalidade. Estes conceitos e seus correlatos - independência, funcionalidade e norma - são utilizados como fundamento tácito para diferenciar algumas variações corporais que são identificadas como estilos de vida diferentes de outras que são, muitas vezes, denominadas de deficiências. Concluímos afirmando que a deficiência pode ser analisada a partir de outras chaves de leitura que não a colocam como sinônimo de doença se considerarmos as noções de interdependência, normatividade e criação de si no mundo como conceitos básicos para descrevê-la.

Palavras-chave Deficiência, Modelo médico da deficiência, Modelo social da deficiência, Autonomia, Normalidade 


\section{Introdução}

A deficiência constitui um campo crescente e heterogêneo de ativismo político e investigação no Brasil e no mundo. No final dos anos sessenta, surgiram em diversos países ocidentais movimentos sociais que reivindicavam os direitos de grupos específicos, como mulheres e negros e, neste contexto, a politização das pessoas com deficiências ganhou força. Na África, América Latina, América do Norte e Europa, os movimentos sociais que reivindicavam igualdade de oportunidades e de direitos para as pessoas com deficiências ficaram conhecidos como Disability Rights Movement. Na Inglaterra nasceu o Union of The Physically Movement Against Segregation (UPIAS) ${ }^{1}$ e nos Estados Unidos da América foi organizado o Independent Living Movement (ILM)2 ${ }^{2}$. O âmbito do território investigativo, por sua vez, é conhecido no mundo anglo-saxônico como Disability Studies e é marcado sobretudo por uma visão crítica da noção de deficiência utilizada por médicos, educadores e outros especialistas e por estudos que lidam com aspectos legais da deficiência.

Um exemplo da expressividade dos estudos críticos foi a relevância que ganharam seus questionamentos à linguagem sobre a deficiência utilizada na Classificação Internacional de Lesão, Deficiência e Handicap (ICIDH) proposta pela Organização Mundial de Saúde (OMS), em 1980. Os críticos reivindicavam a descrição da deficiência como uma questão de direitos humanos e não apenas biomédica. Neste momento a interpelação de natureza política tinha como um dos principais alvos a relação de causalidade entre impairments, disabilities e handicaps assumida pela ICIDH. De acordo com a mesma, impairments significava perda ou anormalidade de uma estrutura ou função corporal - psicológica, fisiologia ou anatômica; disability significava a restrição ou perda da capacidade de performance de atividades de forma considerada normal para os seres humanos e handicap era a desvantagem de uma pessoa individual oriunda do impairment ou da disability que a limita de desempenhar um papel que é normal em determinado grupo ${ }^{3}$.

Para os críticos, a afirmação da relação de causalidade entre essas condições refletia a soberania da linguagem biomédica e a ênfase em propostas curativas. Como resultado da revisão da ICIDH, em 2001, foi aprovada a Classificação Internacional de Funcionalidade, Incapacidade e Saúde $(\mathrm{CIF})^{4}$. O documento é um marco na legitimação de um modelo interpretativo da deficiência com foco nas barreiras e na restrição de participação social de pessoas com deficiências, o qual ficou conhecido como Modelo Social da Deficiência ${ }^{5}$. De uma categoria estritamente biomédica na ICIDH, a deficiência assumiu um caráter também sociológico e político na CIF.

Os debates sobre o sentido de "deficiência" não se esgotaram com a aprovação da CIF. Ademais, como vemos, o termo deficiência desaparece nesta classificação e os termos funcionalidade e incapacidade ganham destaque. A proposta da OMS é que a CIF não seja apenas para aqueles com deficiências, sendo sobre todas as pessoas. $\mathrm{O}$ que está em causa, portanto, é a relação do indivíduo com a sociedade e, neste artigo, preocupanos essa questão.

Com vistas à inclusão social e à cidadania plena e efetiva dos deficientes, no ano de 2015, o Brasil instituiu a Lei Brasileira de Inclusão da Pessoa com Deficiência, também conhecida como Estatuto da Pessoa com Deficiência ${ }^{6}$, que entrou em vigor em janeiro de 2016. A Lei garante, entre outras coisas, condições de acesso à educação e à saúde e estabelece punições para atitudes discriminatórias contra essa parcela da população.

Apesar das conquistas sociais e dos avanços no que diz respeito aos direitos que estão sendo assegurados aos deficientes nos parece importante manter e aprimorar as críticas sobre os enfoques médico e social da deficiência. Segundo o Estatuto da Pessoa com Deficiência, a avaliação da deficiência deve ser médica e social; enquanto a primeira enfatiza as funções e estruturas do corpo para caracterizar a deficiência, a segunda pondera sobre os fatores ambientais e pessoais envolvidos. Ambas, diz o Estatuto, devem levar em consideração a limitação do desempenho das atividades segundo suas especificidades.

A proposta deste artigo é, partindo de uma perspectiva crítica, problematizar as noções de (limitação de) desempenho e de (limitação da) funcionalidade, por meio dos conceitos de autonomia e normalidade. Neste sentido, o trabalho situa-se no campo reflexivo da saúde coletiva que, alimentada pelos pressupostos das ciências humanas e sociais, toma a constante problematização dos conceitos de normal e patológico como um de seus aspectos fundamentais.

\section{Breve Histórico dos Disability Studies: do Modelo da Tragédia Pessoal à Crítica Social}

Portadores de um corpo marcado pela diferença foram, por um longo período do pensamento ocidental, compreendidos como inváli- 
dos, anormais, monstros ou degenerados e seus corpos eram entendidos misticamente como resultado da ira ou do milagre divinos. A anomalia, sobretudo a congênita, era vista como corporificação da ira dos deuses e o destino do sujeito era a morte imediata ${ }^{7}$.

Com a entrada da narrativa biomédica sobre o corpo na modernidade o discurso religioso sobre o excêntrico perdeu força e o corpo atípico passou a ser diagnosticado como patológico ou deficiente, buscando-se o saber e o controle sobre o mesmo. Doravante, discursos doutos de caráter científico tomam os corpos que não se encaixam nos padrões estéticos ou funcionais da média da sociedade como objeto de saber/poder e os rotulam como anormais, isto é, corpos que não são apenas diferentes, mas que devem ser "corrigidos" 8 . Diferentes expressões da atipia se transformam, paulatinamente, em imagens da deficiência.

A compreensão da deficiência como um fenômeno no âmbito da patologia ficou conhecido como o Modelo Médico da Deficiência ou Modelo da Tragédia Pessoal. Desta perspectiva, a desvantagem vivida pelos deficientes é efeito de desvantagens naturais inerentes aos contornos do corpo e, portanto, seus impedimentos são reconhecidos como infortúnios privados, uma tragédia pessoal'. Diversos autores, porém, criticam este ponto de vista e afirmam que a narrativa da tragédia pessoal envolve a ideia de incapacidade pessoal e corrobora práticas medicalizadas e individualizadas para lidar com a deficiência ${ }^{10}$.

Em confronto com tal perspectiva, em 1960 tem início o Movimento do Direito dos Deficientes, quando se iniciou a reivindicação da participação de pessoas deficientes na pesquisa e nas decisões políticas referentes a este grupo. $\mathrm{O}$ Movimento defendeu o estabelecimento de um novo campo acadêmico que foi denominado no mundo anglo-saxão de Disability Studies ${ }^{11}$.

Segundo Gareth Williams ${ }^{12}$, os Disability Studies são marcados pelas correntes teóricas marxista e feminista pós-estruturalista e por duas ênfases principais: a opressão social da pessoa deficiente e a construção cultural e ideológica dos corpos atípicos. Grosso modo, pode-se dizer que a opressão dos deficientes foi trabalhada, sobretudo, pelos teóricos da primeira geração do modelo social, os quais tinham forte inspiração no materialismo histórico e explicavam a opressão por meio de valores centrais do capitalismo relacionados aos corpos produtivos e funcionais. Os principais teóricos dessa geração eram homens adultos, brancos e portadores de lesão medular 5 .
Por outro lado, a construção cultural e ideológica dos corpos atípicos foi trabalhada principalmente pela segunda geração do modelo social da deficiência marcada pelas abordagens feministas e culturalistas. Nestas, os impedimentos intelectuais e o cuidado estavam no centro das discussões e buscou-se desafiar a cultura da normalidade ${ }^{5,13}$.

Na década de 1970, impulsionada por Paul Hunt, sociólogo deficiente físico, foi constituída a primeira organização política sobre a deficiência formada e gerenciada por deficientes, denominada Union of the Physically Impaired Against Segregation $^{1}$. Esta questionava a compreensão biomédica tradicional da deficiência como um problema individual e afirmava que a experiência da deficiência não era resultado da lesão individual, mas de uma sociedade hostil à diversidade humana ${ }^{10,14}$.

Em 1980, a rejeição ao modelo médico e à ideia de que a deficiência precisa ser "corrigida" ganha força, assim como a defesa de que os “ajustamentos" não deveriam ser dos indivíduos deficientes, mas da sociedade, pois ela que era desajustada em relação a estes. Entendia-se que a opressão social e a exclusão dos deficientes não resultavam de suas limitações físico-mentais e que a experiência da desigualdade apenas se manifesta em uma sociedade pouco sensível à diversidade de estilos de vida. Neste contexto, marcado pela "primeira geração" dos acadêmicos e ativistas da deficiência, os estudiosos atentam para a complexidade do conceito de deficiência que, longe de ser sinônimo de um corpo com lesão, também denuncia a estrutura social que oprime a pessoa que apresenta um corpo atípico. Em contraposição ao modelo médico da deficiência, cresce o modelo social da deficiência.

Para os defensores do Modelo Social o corpo atípico não é um destino de exclusão ${ }^{15}$. Habitar um corpo anômalo é uma experiência singular que pode ser descrita de diversas formas, dependendo da experiência subjetiva e do aporte ambiental. Se o prejuízo sofrido pelos deficientes for analisado como resultado da sociedade, as pessoas com deficiência serão vistas como membros de uma minoria cujos direitos foram violados por uma maioria injusta. Assim, o foco da atenção aos deficientes seria permitir às pessoas com deficiência liberdade para participar da vida social e das oportunidades ${ }^{13}$.

Para alguns mais radicais, como Palacios e Romañach ${ }^{16}$, a deficiência é fonte de orgulho e empoderamento, um símbolo de identidade pessoal enriquecida. Ela é vista como diversidade corporal e funcional e como diferença subjetiva. 
Para estes, a experiência da "deficiência" proporciona um sentido de comunidade que é aproveitado na intenção de exaltar os valores fundamentais da vida, os direitos humanos e a celebração da diferença ${ }^{17}$. Trata-se de mais uma expressão de um fenômeno cultural que se desenvolveu nas últimas décadas que foi a emergência de movimentos de defesa de plena cidadania daqueles que falam em nome da diferença. Indivíduos com conformações corporais e/ou mentais anteriormente classificadas como patológicas reivindicam o estatuto de singularidades atípicas não patológicas.

Desenvolve-se a ideia da "deficiência como cultura" e como "categoria diversa" similar à raça e orientação sexual. O campo passa a ter afinidades com disciplinas que lidam com noções de identidade política, como os estudos de gênero e de diversidade sexual ${ }^{10}$. Portanto, a forma de compreender e tratar a deficiência passou a ser comparada com outras formas de humilhação e opressão pelo corpo como o sexismo e o racismo. Neste sentido, cria-se o neologismo disablism para denunciar a cultura da normalidade que oprime e discrimina os portadores de impedimentos corporais ${ }^{17}$.

A tomada de consciência desse movimento vem produzindo processos de coming out deficiente, análogos aos coming outs de gays, lésbicas e negros, declarando um "orgulho deficiente". A afirmação "sou deficiente" constitui uma afirmação de autocategorização, um processo de subjetivação e de formação de identidade. Para os teóricos do campo essa afirmação permite um deslocamento do discurso dominante da dependência e anormalidade para a celebração da diferença e o orgulho da identidade deficiente ${ }^{18}$. Trata-se tanto de um compromisso coletivo e político de protesto contra as barreiras sociais incapacitantes encaradas pelos indivíduos com algum tipo de lesão, como de uma transformação da identidade pessoal vivenciada com orgulho.

Por outro lado, "passar por" (passing) é o termo usado para descrever aqueles que escondem os seus prejuízos (impairments) ou não querem "sair do armário" (come out) enquanto deficientes. Ambivalências identitárias como estas e as diferentes experiências de pessoas que vivem com alguma deficiência são frequentemente ignoradas por ativistas radicais dentro do movimento da deficiência e desclassificadas como opressão internalizada ou falsa consciência ${ }^{19}$.

Vemos que, em geral, a dimensão da lesão, isto é, da limitação imposta pelo corpo com algum tipo de redução da funcionalidade, é des- considerada nas perspectivas dos primeiros teóricos da deficiência. Perceber nas estruturas sociais uma importância maior para incorporar a diversidade corporal do que nas vantagens que a biomedicina poderia oferecer ao corpo deficiente fez com que os teóricos ignorassem a dimensão da lesão e da necessidade de cuidados especiais dos deficientes. A entrada das teóricas feministas na discussão - que marcaram a segunda geração dos estudos da deficiência - complexificou a problemática ao considerar a lesão no debate e ao negar a suposição de que todos os deficientes desejam a independência ou são capazes de alcançá-la. Argumentando que todas as pessoas são dependentes em diferentes momentos da vida, algumas feministas introduziram a ideia da igualdade na interdependência como um princípio mais adequado à reflexão sobre questões de justiça para deficientes ${ }^{20}$. A ambição por independência, dizem, é um projeto moral que se adéqua às aspirações das pessoas não deficientes. Mas, autonomia, independência e produtividade não são valores morais inquestionáveis. É preciso considerar a diversidade da experiência de viver em um corpo lesionado ${ }^{21}$.

\section{Deficiência e Autonomia}

A mudança na forma de compreender a causalidade da deficiência, deslocando a desigualdade do corpo para as estruturas sociais fragilizou a autoridade dos discursos curativos e abriu possibilidades analíticas para uma redescrição do significado de habitar um corpo com deficiências ${ }^{17}$. A passagem simbólica do tema da deficiência do espaço doméstico para o público forçou a questão sobre que tipo de sociedade pode garantir os direitos específicos das pessoas com determinados tipos de impedimentos sem que sejam considerados sujeitos de "segunda categoria".

Nosso ponto de vista leva em consideração o trabalho do filósofo sueco Lennart Nordenfelt ${ }^{22,23}$ e segue a linha argumentativa da segunda geração dos estudos da deficiência. Uma das grandes controvérsias entre os estudiosos da deficiência é sobre a necessidade de desacoplar a análise da mesma de dentro do quadro conceitual epistemológico da saúde e da doença. Os defensores do Modelo Social tiveram o mérito de rechaçar o modelo biomédico hegemônico da análise sobre a deficiência, mas teorias que aproximam a doença da deficiência não se restringem a este modelo.

Nordenfelt, por exemplo, trabalha os conceitos de saúde e doença de forma holística e dialoga com os estudiosos da deficiência. $\mathrm{Na}$ concepção 
do autor, deficiência e doença não são condição da natureza humana, termos a-históricos ou atemporais; elas são categorias construídas por uma determinada sociedade e estão sujeitas a julgamentos de valor ${ }^{22}$. A seu ver, autonomia é um valor social central na caracterização da saúde e o conceito de deficiência que importa à medicina é igualmente valorativo, podendo ser entendido a partir do mesmo quadro conceitual.

A teoria da saúde de Nordenfelt é fortemente influenciada pela noção de dignidade e se baseia na ação pragmática do sujeito no mundo, considerando o terreno da manifestação afetiva do ser humano e o bem-estar. O autor faz referência a um tipo de dignidade que denomina de dignidade de identidade que está ligada à integridade e à autonomia do corpo e da mente do ser humano e, em alguns casos, à sua autoimagem.

Em sua concepção, a saúde de uma pessoa está ameaçada quando sua integridade corporal está comprometida, temporária ou permanentemente, a ponto de impossibilitá-la de cumprir seus projetos de vida, os quais denomina de "metas vitais". A especificação das metas vitais deve ser deixada à avaliação do bem-estar, a qual é sui generis. A avaliação sobre os graus mínimos de bem-estar é realizada sobre as bases de uma cultura comum, mas os valores ligados às metas vitais são muito mais egocêntricos, isto é, relacionam-se com a satisfação do próprio agente e não necessariamente com a prescrição da sociedade ${ }^{24}$.

Por outro lado, não são quaisquer projetos individuais que são legítimos, diz. Eles não podem destoar muito dos projetos hegemônicos da cultura em que a pessoa está inserida. Pessoas da mesma cultura tendem a fazer uma avaliação parecida sobre o que é uma vida boa. Há certo consenso sobre os graus mínimo e desejável de bem-estar. Este, entre outras coisas, diz Nordenfelt $^{22}$, equivale a especificar o que é considerada a fronteira entre a saúde e a doença.

Portanto, o que, em última instância, fundamenta a análise se estamos diante de uma condição apenas atípica ou patológica é a avaliação da autonomia. Segundo Nordenfelt, se a pessoa não consegue cumprir suas metas vitais devido a um comprometimento corporal, estamos diante de alguém que não está em boa saúde ou é deficiente, o que realça o valor pressuposto de sujeito autônomo para a definição da deficiência.

Apesar de Nordenfelt não o fazer explicitamente, dissociar o campo da doença do campo da deficiência é fundamental. A ruptura com o olhar médico marcado pela dicotomia entre normal e patológico no terreno da deficiência foi um importante avanço proporcionado pelos teóricos do Modelo Social, pois permitiu recusar a descrição do corpo com impedimentos como patológico. Partindo desse pressuposto - de que o corpo com impedimentos não é necessariamente patológico - parece-nos que o trabalho de Nordenfelt nos traz um outro desafio fundamental para o avanço na discussão sobre a noção de deficiência: a problematização do valor moral dos estilos de vida e da concepção de autonomia que sustenta os discursos sobre a deficiência.

Parece-nos que um dos pontos chave das teorias sobre a deficiência para a consideração de alguém como deficiente é se a condição corporal atípica prejudica o exercício da identidade social dominante que é de um sujeito livre e autônomo. Nesta perspectiva, a pessoa é deficiente quando a mesma não pode andar por si, não pode cumprir, de forma independente, os projetos que a corrente principal da cultura considera dignos.

Tauber ${ }^{25}$ nos ajuda neste debate ao estabelecer as bases para a discussão da autonomia, explorando como ela pode ser designada como uma característica do self. $\mathrm{O}$ autor apresenta duas maneiras distintas de entender a identidade pessoal: a partir do self atomístico e a partir do self relacional.

O self atomístico é o self altamente individualista para o qual o princípio da autonomia assume uma característica central da identidade pessoal. Baseia-se na ideia de um agente neutro, racional, independente e objetivo fruto da filosofia liberal de John Locke, que considera o sujeito cognoscente como radicalmente separado do mundo. $\mathrm{O}$ self atomístico, diz Tauber, é adequado ao ethos político liberal, que entende o autogoverno como um novo e fundamental valor, temperado apenas pela infração à liberdade de outros.

A supervalorização da individualidade em detrimento da sociabilidade, manifestada no alto valor dado ao indivíduo e no desprezo ao valor das redes de reciprocidade é uma marca do self individualista. Dado o elevado valor concedido à independência de pensamento e à liberdade de escolha, a visão do self como individualista se tornou um princípio básico da filosofia Iluminista. O self atomístico demanda que cada um de nós seja o criador de sua própria identidade, havendo, portanto, uma celebração da primazia do self sobre o viver coletivo.

Mas Tauber mostra que o sujeito pode ser compreendido a partir de outro referencial. Trata-se da concepção do sujeito como produto do encontro com o outro. Nesta matriz, há outra representação do self: o self relacional ou self so- 
cial. O self nessa representação é entendido como uma confluência de relações e obrigações sociais constitutivas da identidade. Somos, fundamentalmente, traços de identificações com os outros e a autonomia é um valor subordinado a tais princípios morais. Nesta concepção, não há um self a ser revelado, ou uma identidade que reside separada da experiência intencional com o outro. Para Mead $^{26}$, por exemplo, o self é um processo social individualmente interiorizado. A relação com o outro é a unidade básica para a construção do self.

Trata-se claramente de uma disputa ideológica. A concepção atomística do ser humano considera a confiança, a amizade, a lealdade, o cuidado e a responsabilidade atributos secundários em relação à autodeterminação e à autorrealização.

A segunda geração dos estudiosos da deficiência marcada pelas teóricas feministas da área assimila que a ambição por independência é um projeto moral que se adéqua às aspirações das pessoas não deficientes e que ela não é um valor inquestionáve ${ }^{22}$. A demanda por justiça não pode ser referida à ética individualista subordinada à hipervalorização da ideia de independência. Criticam a primeira geração do Modelo Social por priorizar a inclusão dos deficientes na lógica capitalista em detrimento da problematização dos pressupostos morais da organização social que gira em torno do trabalho e da independência ${ }^{5}$. Negando a suposição de que todos os deficientes desejam a independência ou são capazes de alcançá-la, introduziram a ideia da igualdade na interdependência como um princípio mais adequado à reflexão sobre questões de justiça para deficientes ${ }^{20}$.

A filósofa feminista Eva Kittay ${ }^{20,27}$ preocupase em desmontar as teorias liberais da justiça e igualdade, ao sustentar que as relações de dependência são inevitáveis na vida social e inescapáveis à história de vida de todas as pessoas. Cuidado e interdependência, diz, são princípios que estruturam a vida social e impõem a centralidade da dependência nas relações humanas.

A autora americana fez uso da ideia de que "somos todos filhos de uma mãe" para dizer que todos somos cuidados por alguém em algum momento da vida. A partir da noção de self transparente, isto é, do self moral daquele que tem o dever de cuidar de outras pessoas e é movido por um ideal altruísta, baseado nos laços de afeto e preocupação, reitera que o sujeito moral é inerentemente relacional, contrapondo-se à interpretação de self da tradição liberal. Nesta concepção, o self transparente é o elemento moral central da ética do cuidado.
Trata-se de uma forma de compreender o indivíduo e a moralidade diferente da definição tradicional do ser humano nas sociedades capitalistas ocidentais, em que o indivíduo é prioritariamente percebido como sujeito independente, submetido apenas a si mesmo e ao comando da razão.

Nesta concepção, o cuidado também é uma demanda de justiça social. Afirmando que as relações de dependência são incontornáveis e que o discurso da absoluta independência é perverso, posto que implique o desamparo como horizonte de nossas debilidades, o estudo da autora ajuda a ver o indivíduo autônomo como aquele que exerce uma escolha autônoma e não obrigatoriamente como aquele que é capaz de agir de forma independente.

Esvaziar as noções de capacidade individual e independência e fortalecer as ideias de interdependência e relação interpessoal como critérios de julgamento da condição variante permitem que o julgamento da deficiência seja relativizado.

\section{Deficiências, Normalidades e Normatividades}

A segunda geração dos estudos da deficiência trouxe a contribuição de realçar que a dependência é um fenômeno universal e que a percepção da mesma está relacionada às dependências que consideramos (i)legítimas em determinada sociedade. Pressupondo a ideia de eficiência ou capacidade, a conceitualização da deficiência traz o problema de demarcar quais são as capacidades que queremos e quem as define.

De fato, na $\mathrm{CIF}^{4}$ um dos conceitos fundamentais para a caracterização da deficiência é a participação, que pode ser indicada pela avaliação do desempenho do indivíduo no meio em que vive, este último termo usado explicitamente no Estatuto da Pessoa com Deficiência, de $2015^{6}$. Neste sentido, pode-se dizer que não é a natureza que oprime, mas a cultura da normalidade que descreve algumas performances como indesejáveis.

A pergunta que se faz necessária é quais performances são consideradas aceitáveis e quais devem ser "reparadas". O filósofo Ron Amund$\operatorname{son}^{28}$ nos oferece alguns indícios. Aproveitando o trabalho de Stokoe ${ }^{29}$ que demonstra que a linguagem dos sinais tem a complexidade estrutural e os poderes cognitivos e expressivos da linguagem falada e que injúrias cerebrais que causam certos tipos de afasias na linguagem falada têm efeito similar na linguagem dos sinais, Amundson propõe duas formas de interpretar esta con- 
dição. A mais comum é a compreensão de que a capacidade da linguagem é inata e evolutivamente vinculada ao som vocal e, desta maneira, as pessoas têm uma grande flexibilidade refletida na aplicação da capacidade inata em um domínio estrangeiro. Outra forma de apreender a questão é considerar que a capacidade da linguagem não é inatamente associada ao som vocal, mas é de tal forma abstrata que pode ser aplicada indiscriminadamente às linguagens falada ou de sinais. Ambas as interpretações negam o determinismo funcional biológico e sugerem que o potencial expressivo dos seres humanos é muito maior do que se imagina. Temos, por exemplo, a capacidade de construir o mundo sem fala sonora. Apesar disso, os surdos são considerados deficientes.

Amundson faz então uma diferenciação entre "nível" e "modo" de performance ou desempenho e mostra-nos que é possível ter "exemplares da mesma espécie” com design diferentes e que tenham um desempenho funcionalmente idêntico no nível de expressão, mesmo que o estilo da performance seja diferente. O design da espécie, diz, permite que alguém conviva com prótese e essa variação pode, inclusive, permitir um nível de performance melhor, como é o caso de corredores portadores de prótese de perna de titânio.

Amundson quer chamar atenção de que podemos alcançar o mesmo fim com funções diferentes, que nada mais é do que a extensão do conceito de performance aceitável. O autor sugere que o conceito de normalidade da espécie seja substituído pelo conceito de responsividade, que seria uma normalidade individual. A normalidade individual indica que se estabelece a noção de norma em função de uma média e o autor quer desatrelar sua teoria da estatística, evitando qualquer referência ao cientista belga Adolphe Quetelet, que transferiu os modelos explicativos da astronomia para a antropometria, proporcionando uma mudança do estatuto epistemológico da distribuição normal. Quetelet propunha que medições de casos representativos de uma população permitiria descobrir o "homem médio" da população investigada em suas dimensões física, intelectual e moral. A noção de tipo humano ou de "homem médio", por sua vez, era usada como padrão para análises sociológicas.

Amundson chama de "modo ou estilo" ou de "responsividade" o que Canguilhem ${ }^{30}$ chama de instauração de uma nova norma ou normatividade de cada organismo. Normatividade é um termo caro da obra de Canguilhem e, apesar de ter sido elaborado para lidar com a problemática da saúde e da doença, parece-nos fundamental para a reflexão sobre a deficiência na medida em que o objeto de análise proposto pelo autor é a normalidade.

Inspirado no trabalho de Kurt Goldstein $A$ Estrutura do Organismo, Canguilhem aproveita a ideia de que a norma importante para a saúde é a "norma individual", aquela que toma o indivíduo como padrão. A saúde, para Goldstein, é concebida como "adaptação ao meio pessoal" e a doença como uma modificação qualitativa que leva a um "estreitamento" desse meio. A "cura" não é idealizada como um retorno a um estado prévio, mas como ascensão a uma "nova norma individual”. Goldstein, então, sugere a distinção entre "anomalia" e "doença": enquanto a primeira é um desvio de uma norma supraindividual, a segunda refere-se à individualidade pessoal ${ }^{31}$.

Aproveitando o trabalho do médico alemão, Canguilhem afirma que a norma individual é oriunda da relação entre o organismo individual e o seu ambiente. A pessoa doente é uma pessoa cujo ambiente é "estreito" em comparação com aquele de uma pessoa "normal" e, então, cunha o termo normatividade para se referir à habilidade do organismo de adotar novas normas de vida. A saúde, nesta concepção, é a margem de tolerância às inconsistências do ambiente, a possibilidade de transcender as normas. O normal é a normatividade, a capacidade de adaptação, de variação do organismo às mudanças circunstanciais dos meios externo e interno. Assim, a patologia não é uma unidade propriamente objetiva. A única unidade que se pode ter e que não é puramente objetiva é a de um ser vivo, que é um corpo vivo em permanente relação com o meio; relação variável com um meio variável ${ }^{32}$.

Segundo Klautau et al. ${ }^{33}$ devemos entender a normatividade como aquilo que individualiza o ser vivo, biológica e psicologicamente. O ser vivo deve ser pensado a partir da noção de potência, isto é, os organismos desenvolvem suas potências através de seus comportamentos particulares. Estes, diz a autora, não são apenas respostas automáticas a estímulos externos, são modos singulares de se relacionar com o meio que todo ser vivo explora à sua maneira. E é na ação do indivíduo no mundo que devemos procurar as referências para descrever e compreender o alcance das modificações impostas pela patologia. Assim, só existe para o vivo normalidade na referência a um meio.

Tomando como base a ideia de normatividade para pensar a deficiência torna-se imprescindível considerar o meio como um aspecto fundamental. Não é apenas a problematização da 
noção de autonomia que é relevante para abalar nossas certezas sobre a natureza da deficiência. A relação entre as ofertas do meio e a capacidade individual é igualmente importante. A sociedade constitui o contexto de ação dos indivíduos, pois o background do ambiente pode favorecer a execução de certa ação, pode torná-la mais difícil ou impossibilitá-la.

Em muitos casos, a suposta falha no desempenho pode ser reparada pela tecnologia aplicada pelos humanos. É o caso dos óculos, dos aparelhos de surdez, da comunicação de autistas facilitada por computador e das inúmeras próteses. A ação deliberada de adequação do meio para manutenção de uma vida satisfatória permite que o disfuncional em alguns casos se torne perfeitamente funcional. E, desse prisma, o saudável pode ser entendido, à maneira de Canguilhem, como normativo, isto é, capaz de enfrentar as injúrias do meio a partir da criação de novas normas de funcionamento. Para Canguilhem, o vivente não se adapta mecanicamente ao meio, confronta-se com o meio, o transforma e se transforma. Cabe a nós acolhermos ou não o diferente, criando condições de estímulo às respostas normativas dos sujeitos individuais. Como diz Canguilhem ${ }^{34}$ :

"Num certo sentido, não há seleção na espécie humana, uma vez que o homem pode criar novos meios em vez de suportar passivamente as mudanças do antigo. Em outro sentido, a seleção no homem alcançou sua perfeição limite, visto que o homem é este vivente capaz de existência, de resistência, de atividade técnica e cultural em todos os meios".

Mas a fabricação e a incorporação tecnológicas não parecem suficientes para o atípico se tornar normal. Amundson ${ }^{28}$ sugere que o julgamento da normalidade costuma se basear no modo e não no nível de desempenho, isto é, aspectos cosméticos do aspecto funcional importam mais do que aspectos pragmáticos no julgamento de atipia biológica como anormalidade ou deficiência. A grande fascinação pelo modo de funcionamento, ou pela normalidade estética é ela mesma um obstáculo para a performance funcional, o que demonstra o preconceito por formas diversas de experimentar o corpo e de agir no mundo através dele. A doutrina da normalidade biológica e a falácia da normalidade funcional são sustentadas por uma ideologia que visa manter os corpos atípicos relegados ao ostracismo social.

Parece-nos, portanto, mais interessante em termos éticos e políticos - considerar, assim como faz Canguilhem ${ }^{30}$, a deficiência como modalidade de vida qualitativamente distinta. Deste aspecto, o deficiente não deve ser ajustado à norma social, mas deve ter o direito de normalizar por si mesmo sua própria vida de acordo com suas potencialidades.

\section{Considerações Finais}

Neste artigo pretendemos mostrar como as noções de autonomia e normalidade ajudam a problematizar a noção de deficiência.

O conceito de autonomia nos parece útil para a reflexão sobre a deficiência a partir de dois eixos de análise interligados. O primeiro refere-se à consideração da autonomia como conceito chave para a caracterização de uma condição corporal atípica como normal ou patológica. É precisamente tal consideração que permite retirar a deficiência da condição de doença, pois muitos sujeitos que possuem variações corporais podem realizar suas metas vitais, como diz Nordenfelt. Isso se dá, sobretudo, quando se modifica o comportamento mediano e o equipamento do ambiente que em geral não atendem às pessoas atípicas.

Mas há outra dimensão da questão que nos leva ao segundo eixo de análise. Quando identificamos a deficiência com o impedimento de realização dos projetos pessoais permitimos que os projetos sejam descritos de outra forma, devendo ser alargados. Para tanto, é necessário redefinir a ideia de autonomia para deixar fluida a fronteira entre eficiência e deficiência. Tauber ${ }^{25}$ nos mostra que ao invés de pensar a autonomia como soberania, podemos considerá-la dentro de uma ética de cuidado, de dependência e participação. Entender autonomia nestes termos permite preservar a atipia, a priori, como diferença e não como doença ou deficiência.

No que se refere à noção de normalidade, demonstramos que é uma noção altamente controversa e que pode ser entendida a partir de diferentes referenciais. No caso da caracterização de determinada condição como deficiente, parece-nos que o sentido de normalidade utilizado está próximo daquele de capacidade. Vemos que são determinadas performances - consideradas normais ou anormais de acordo com a cultura da normalidade subjacente - que darão suporte à noção de deficiência.

Apontamos o trabalho de Amundson como referência importante para a compressão sobre quais performances são consideradas aceitáveis e quais devem ser "reparadas". O autor denomina de "normalidade cosmética" a cultura da 
normalidade que sustenta a ideia de atipia como deficiência e discrimina socialmente os sujeitos diferentes.

Neste sentido, parece-nos mais interessante considerar os corpos atípicos a partir da noção de normatividade de Canguilhem e, neste sentido, o meio - não apenas biológico, mas também social - em que a pessoa vive é um aspecto fundamental para a caracterização da condição. Considerar a deficiência tendo como referência a noção de normatividade ao invés da noção de normalidade é também uma forma de escapar da "ontologia negativa" inerente ao modelo médico da deficiência que identifica a deficiência como um infortúnio privado e, ao mesmo tempo, escapar do radicalismo do modelo social que tende a eclipsar a dimensão biológica da deficiência. A normatividade como conceito fundamental para se pensar a deficiência permite que a mesma seja avaliada de acordo com o caráter criativo da vida e que a diversidade de estilos de vida seja compreendida como um valor moral positivo.

\section{Colaboradores}

P Gaudenzi e F Ortega participaram de todas as etapas de produção do artigo. 


\section{Referências}

1. Union of the Physically Impaired Against Segregation (UPIAS). Fundamental principles of disability. London: UPIAS; 1976.

2. Shakespeare T. La auto organización de las personas con discapacidad: ¿un nuevo movimiento social? In: Barton L, organizador. Superar las barreras de la Discapacidad: 18 años de "Disability and Society". Madrid: Morata; 2008. p. 68-85

3. World Health Organization (WHO). International classification of impairments, disabilities, and handicaps. Geneva: WHO; 1980.

4. World Health Organization (WHO). International classification of functioning, disability and health. Geneva: WHO; 2001.

5. Diniz D. O que é deficiência. São Paulo: Editora Brasiliense; 2007.

6. Brasil. Lei 13.146 de 06 de julho de 2015. Institui a Lei Brasileira de Inclusão da Pessoa com Deficiência (Estatuto da Pessoa com Deficiência). Diário Oficial da União 2015; 7 jul.

7. Braddock DL, Parish SL. An Institutional History of Disability. In: Albrecht GL, Seelman KD, Bury, M, editors. Handbook of Disabilty Studies. London: Sage; 2001. p. 11-68.

8. Foucault M. Os Anormais: Curso no Collège de France (1974-1975). São Paulo: Martins Fontes; 2002.

9. Barnes C, Barton L, Oliver M. Disability studies today. Cambridge: Polity Press; 2002.

10. Oliver M. The Politics of Disablement. London: Macmillan; 1990.

11. Ralston DC, Ho J. Philosophical reflections on disability. New York: Springer; 2010

12. Williams G. Theorizing disability. In: Albrecht GL, Seelman KD, Bury, M, editors. Handbook of Disabilty Studies. London: Sage; 2001. p. 123-144.

13. Corker M, Shakespeare T. Mapping the terrain. In: Corker M, Shakespeare T. Disability/postmodernity: embodying disability theory. Londres: Continium; 2002. p. 1-17.

14. Shakespeare T. The Social Model of Disability. In: Davis LJ, editors. The Disabilty Studies Reader. New York: Routledge; 2010. p. 214-221.

15. Tremain S. Foucault and the Government of Disability. Ann Arbor: The University of Michigan Press; 2005.

16. Palacios A, Romañach J. El modelo de la diversidad. La bioética y los Derechos Humanos como herramientas para alcanzarla plena dignidad en la diversidad funcional. Madrid: Ediciones Diversitas-AIES; 2006.

17. Diniz D, Barbosa L, Santos WR. Deficiência, direitos humanos e justiça. Sur, Rev. int. direitos human 2009. 6(11):64-77.

18. Swain J, Cameron C. Unless otherwise stated: discourses of labeling and identity in coming out. In: Corker M, French S, editors. Disability discourse. Buckingham: Open University Press; 1999. p. 68-78.
19. Shakespeare R. Disability Rights and Wrongs. Abingdon, New York: Routledge; 2006.

20. Kittay EF. Dependency, Difference and the Global Ethic of Longterm Care. J. Political Philos 2005; 13(4):443469.

21. Morris J. Pride Against Prejudice. London: Women's Press; 1991.

22. Nordenfelt L. On the Nature of Health: An Action-Theoretic Approach. Dordrecht: Kluwer Academic; 1995.

23. Nordenfelt L. On disability and Illness: a reply to Edwards. Theor Med Bioeth 1999; 20(2):181-189.

24. Giroux E. Después de Canguilhem: definir la salud y la enfermedad. Bogota: Universidad El Bosque; 2011.

25. Tauber A. Patient Autonomy and the Ethics of Responsibility. Cambridge: MIT Press; 2005.

26 Mead G. Mind, self and society: from the standpoint of a social behaviorism. Chicago: The University of Chicago Press; 1962.

27. Kittay EF. At the Margins of Moral Personhood. Journal of Bioethical Inquiry 2008; 5(2):137-156.

28. Amundson R. Against normal function. Stud. Hist. Phil. Biol. \& Biomed. Sci. 2000; 31(1):33-53.

29. Stokoe WC. Sign Language Structure: An Outline of the Communication Systems of the American Deaf. Journal of Deaf Studies and Deaf Education 2005; 10(1):3-37.

30. Canguilhem G. O Normal e o Patológico. Rio de Janeiro: Forense Universitária; 1995

31. Gayon J. The concept of individuality in Canguilhem's philosophy of biology. J. Hist. Biol 1998; 31(3):305-325.

32. Portocarrero V. As Ciências da Vida: de Canguilhem a Foucault. Rio de Janeiro: Editora Fiocruz; 2009.

33. Klautau P, Winograd M, Bezerra Júnior B. Normatividade e plasticidade: algumas considerações sobre a clínica psicanalítica com pacientes neurológicos. Fortaleza: Revista Mal-estar e Subjetividade 2009; IX(2):551574.

34. Canguilhem G. O conhecimento da vida. Rio de Janeiro: Forense Universitária; 2012.

Artigo apresentado em 24/01/2016

Aprovado em 27/06/2016

Versão final apresentada em 29/06/2016 